\title{
Social Energy and Trust
}

\author{
Jiayi Song ${ }^{1}$ \\ ${ }^{1}$ Experimental HS Attached to Beijing Normal University, Beijing, China \\ Correspondence: Jiayi Song, Experimental HS Attached to Beijing Normal University, Beijing, China.
}

Received: July 13, 2021

Accepted: July 29, 2021

Available online: August 4, 2021

doi:10.11114/ijsss.v9i5.5316

URL: https://doi.org/10.11114/ijsss.v9i5.5316

\begin{abstract}
Trust is the crucial basis of all interpersonal relationships and is composed of expectation and vulnerability. Its significance within the field of psychology is far-reaching. In 2002, Canavan coined the term social energy to define the distinct psychological phenomenon that occurs when the self $(\mathrm{P})$ and another individual $(\mathrm{O})$ share enthusiasm toward a common object or event (X). In this paper, I investigate the influence of social energy on how individuals rate or rank the trustworthiness of another, as well as the reason for being trusted, in the presence of high and low social energy. The experiment is conducted within a 2X1 ANOVA design by manipulating the different levels of social energy, either high or low. In addition to measuring trust and the reasons for trusting, participants' feelings and emotions were assessed in three hypothetical situations, measuring whether the trust was warranted. The main finding concludes that participants' ratings of another individual's trustworthiness is significantly higher in high social energy conditions, compared to those in low social energy conditions. In addition, the reason for P's doing so is that "I know in high social energy O thinks in the same way as I do," which is reinforced by $\mathrm{CHI}^{2}$ Test results. By assessing emotional variables, it is found that gratitude, positive feelings, expectation, and regrets differ significantly with regard to levels of social energy. In addition, the HSE participant liked and believed the other, and was more kindly disposed than the LSE participant, who tended to be more blaming and punitive.
\end{abstract}

Keywords: trust, common interest, social energy, emotion, prediction

\section{Introduction}

1.1 Trust

"Trust is itself a term for a clustering of perceptions." (White, 1992: 174)

\subsubsection{Definition of Trust}

Within our daily interactions, many decisions people make are based on the evaluation and prediction of others' behaviors. Trustworthiness, whether or not the trustee is to be trusted by the truster, ranks high in these decisions. Thus, the field of psychology has identified interpersonal trust in social contexts with far-reaching significance. Psychologists have yet to agree on the definition of trust, though it is universally agreed that trust is a nuanced cognitive assessment of another's trustworthiness, and that it is made using both conscious and subconscious processes (Hill \& O'Hara, 2006). The key elements in building trust include vulnerability and expectation, and trust is described as "comprising the intention to accept vulnerability based on the positive expectations of the behavior of another" (Rousseau, Sitkin, Burt, \& Camerer, 1998, p. 395). This vulnerability comes from the presupposed risks of the truster granting power, financial values, and social meaning to the trustee, and the possible feelings of loss and regret that are critical elements of a trusting relationship. Similarly, trust without a positive expectation is self-destructive because trusters accept potential risks due to the belief that negative consequences are highly unlikely. Contemporary research examines trust in various fields, including political beliefs (Brewer, 2004), community involvement (Rahn \& Transue, 1998), close relationships (Simpson, 2007), organizational behavior (Kramer, 2007), economic decisions (Evans \& Krueger, 2009), and law and criminal justice (Hill \& O’Hara, 2006).

\subsubsection{How to Build Trust}

Whether or not one would trust someone to do something specific obviously depends on our prediction. Typically, what one believes about how someone else would behave under certain circumstances is determined by directly reflecting upon past behaviors and through verbal communication. In the absence of seeing, being told, or using other methods to gain information about a person, the field of psychology has proposed three alternative processes to describe how people think 
someone else is thinking, or how they think or predict how that person will act.

\subsubsection{Disposition}

When there is little knowledge of one's propensity and past experiences, disposition plays the tune of trust. Rotter (1967) defines dispositional trust as the general expectation that others will behave fairly and responsibly. Trusters tend to be optimistic about trustees' behaviors, expecially in unscripted and novel situations. Sometimes, self-fulfilling prophecies may occur, in which the fact that the trustee is being trusted actually generates his/her trustworthy behaviors. Past research conducted by Deutsch (1949) and his colleagues suggests that people who are untrusting of others may themselves be untrustworthy, when it comes to their own evaluation by others.

\subsubsection{Projection}

Social projection theory suggests that trusters think, without inquiry or evidence, that others would behave the same way as "I" behave, which means individuals base their trustworthiness expectations on their own trustworthiness (Thielmann \& Hilbig, 2014). Projection is the subconscious intuition of evaluating trust in social groups. For example, a trustworthy person might be more willing to place confidence and faith in others, while an untrustworthy individual would be more likely to remain alert and to cooperate with more vigilance. This theory is investigated through testing behavioral tendencies in economic games. Past research measured cooperativeness in the Dictator Game and found a positive association of one's trait Honesty-Humility with their trustworthiness expectations of others.

\subsubsection{Empathy}

A different approach that attempts to see the situation from another's "shoes" is called empathy. The essence of empathy, agreed upon by most researchers of empathy, is "feeling what another person feels because something happens to them" (Wondra \& Ellsworth, 2015). In empathy, one makes every effort to imagine how the other person would behave from the someone else's point of view as a separate person. According to this theory, the trustworthiness of others is based on the predictions of another's behavior that one makes by evaluating one's own situation. The content of empathy thus becomes the basis of evaluating trustworthiness, or to establish a trusting relationship. Empathy could, but does not have to, involve an actual conversation with another.

\subsection{Similarities and Differences between Trust and Fear}

Some scholars propose that trust and fear share a common core, and refer to the latter as aversive trust. While positively believing in the capability of somebody results in trust, fear of authorities, violations and punishments could also lead to the desired outcome (Castelfranchi \& Falcone, 2011). To address this topic with a specific example, the fear of being punished by one's superior or mentor (aversive trust) could incur the same outcome of, for example, trusting one to hand in a homework assignment or completing a delivery for the boss, compared to the prediction made solely from one's original trustworthiness or morality. This investigation explores the prediction that social energy fosters only positive trust, and this will be assessed in the "why trust" questions presented in the questionnaire.

\subsection{Social Energy Theory}

\subsubsection{Introduction to the Theory}

In 2002, Canavan coined the term "social energy", a concept that described the psychic energy generated between "me" (P) and another individual $(\mathrm{O})$, both of whom are aware of their shared enthusiasm and interest in a specific topic or activity (X). Canavan describes this "social energy relationship" within a P-O-X triangle structure, in which each component has strong bilateral relationships with the other components within the social energy structure. In Social Energy Theory, "enthusiasm can be defined as a genuine and pronounced interest, excitement, and participation in a specific target (X)" (Canavan \& Garinther, 2013). The amount of social energy within a group or among individuals is directly proportional to the extent of shared enthusiasm. Social energy does not provide an all-or-nothing phenomenon, but a two-end continuum, in which a highly enthusiastic connection between the participant $(\mathrm{P})$, one or more others $(\mathrm{O})$, and a shared interest $(\mathrm{X})$ generates high social energy, while a more loosely-bonded P-O-X triadic structure would generate low social energy.

C.S. Lewis's publication Surprised by Joy provides a vivid illustration of what social energy is.

"... I found Arthur sitting up in bed. On the table beside him lay a copy of Myths of the Norsemen.

"Do you like that?" said I.

"Do you like that?" said he.

Next moment the book was in our hands, our heads were bent close together, we were pointing, quoting, talking - soon almost shouting - discovering in a torrent of questions that we liked not only the same thing, but the same parts of it and in the same way; that both knew the stab of Joy and that, for both, the arrow was shot from the North. Many thousands of people have had the experience of finding the first friend, and it is none the 
less a wonder; as great a wonder (pace the novelists) as first love, or even a greater. I had been so far from thinking such a friend possible that I had never even longed for one; no more than I longed to be King of England. If I had found that Arthur had independently built up an exact replica of Boxonian world I should not really have been much more surprised. Nothing, I suspect, is more astonishing in any man's life than the discovery that there do exist people very, very like himself."

---- C.S. Lewis

In the descriptions, Arthur (O) and "I" (P) are mutually enthusiastic about the same part of the same book (X) in the same way, creating a powerful resonance and unity. In social energy, the other person knows he/she is the same as us, and the person know that the other person is the same as them, due to the power of X. Lewis also demonstrates how much people value this shared perception, although people do not realize its presence most of the time.

\subsubsection{The Power of Shared X}

$\mathrm{P}$ and $\mathrm{O}$ each have an independent, intrinsic motivation towards $\mathrm{X}$ (activity of shared enthusiasm). Specifically, the effects which result in an individual's relationship with X are referred to as "the power of X." Compared to other relavent psychological theories, such as the Self-Determination Theory (Ryan, Huta \& Deci, 2008), which proposes "the energy available to the self is a salient and functionally significant indicator of both health and motivation," the shared interest $\mathrm{X}$ is unique to social energy. Together with the results of past research, researchers have concluded that the special effects of social energy are the results of the shared $\mathrm{X}$. This motivational dynamic results in a series of significant changes in behavior, cognition, thoughts, emotion, and health conditions in the field of positive psychology and social psychology. Canavan (2001) originally proposed that people involved in social energy would perceive the other and the shared interest more positively, would be more focused and energized, and would experience higher levels of flow. Flow describes a state of "optimal experience arising from intense involvement in an activity that is enjoyable" (Csikszentmihalyi, 1990). The power of the shared X also transforms competition into cooperation because of $\mathrm{P}$ and O's shared value and desire for the welfare of X, even over personal gains (Canavan \& Riggin, 2008). People also feel enhanced feelings of connectivity and cohesion in a social energy group, which is attributed to the power of $X$ as well (Robinson \& Canavan, 2012).

\subsection{Relationships between Trust and Social Energy}

In the well-known story of Solomon's Judgment in the Bible, two women came to King Solomon, both claiming to be the mother of a child. Instead of the usual procedure of directly examining how reliable their claims were and asking for further investigation to decide whom to trust, the king suggested cutting the baby in two, with each woman receiving half. One of them agreed immediately while the other begged the king for mercy, crying and proposing to give the child to her rival. The king was then able to distinguish who was the true mother and could be trusted - obviously, it was the second woman who cried and cared for the baby from the bottom of her heart. In this famous story, King Solomon was, in fact, using social energy to establish trust. He utilized the women (P)'s enthusiasm in the baby's well-being (X) and verified the relationship between $\mathrm{P}$ and $\mathrm{O}$ to trust. In this essay, I will introduce a fourth approach- unique to social energy and different from disposition, projection, and empathy - to the field of psychology, concerning how people build trust. At this time, it does not have a name, and has not been precisely described in literature or in professional writings. In ancient Chinese romantic literature, self-evident knowledge exists between tacit romantic partners who have a similar passion towards the relationship, and the presence of these tacit beliefs is expressed as “xin you ling xi (心有灵犀) ." Similarly, trust is built between people through social energy without thorough communication, guesses, oreliberation. People in social energy could be completely different in all other aspects of life in terms of occupation, age, and background, but at that moment they become each other's "alter-ego," because they 'know' what the other is thinking and what he/she will do with respect to X, and that the other is likely to behave in the same way as themselves. (Alter-ego is, perhaps, at the moment, the closest word that describes the phenomenon.) In addition, $\mathrm{P}$ will utilize O's independent observations of $\mathrm{X}$ as if they were P's own. Different from disposition, projection, and empathy, this shared opinion (alter-ego) offers a new perspective in how people understand or can predict another's behavior, and to recognize that the other person simultaneously knows our mind.

\subsection{Hypothesis and Predictions}

(1) I hypothesize that participants in high social energy (HSE) will rate themselves as more trusting of O (the other) than will those in low social energy (LSE). This is assessed using the question: "How much would you trust Casper to deliver

\footnotetext{
${ }^{1}$ The word “Xin you ling xi (心有灵犀)” was first mentioned in Tang dynasty poet Li Shangyin's poem, originally depicting the emotional and ideological resonance between intelligent lovers. In the contemporary language context of Chinese, this word becomes an idiom describing how different individuals perceives the same thing in the same way and understand what the other is thinking and is about to say with one subtle and tacit hint.
} 
the statue?"; I predict that people in HSE will give a higher ranking on a 5-point-scale than those in LSE. (2) I hypothesize that the reason they are going to give this higher ranking is that he is thinking the same way as "I" is thinking, meaning the intrinsic interest in the common activity opens a "third door" to perceive trust in interpersonal relationships. Under these circumstances, people grant trust through the circuitry of $\mathrm{P}-\mathrm{X}-\mathrm{O}$ instead of $\mathrm{P}-\mathrm{O}$, building trust which is more reliable and solid, but is specifically in regard to X. The second hypothesis would be tested by giving all participants four alternatives, in which they are asked to pick the most corresponding option. If participants in HSE pick "Because he is thinking the same way as I am thinking" while those in LSE do not, the result supports the hypothesis. (3) In addition, I also predict that higher levels of social energy would trigger more positive feelings towards the other, including delight, gratitude, peace, flow, and other measures.

\section{Methods}

\subsection{Participants}

The participants were 80 Asians (46 male, 34 female) who filled out the questionnaire. They were divided equally between experimental conditions (40 HSE and 40 LSE). Ages ranged from 11-60. Among them, 68 identified themselves as Chinese citizens, and the questions were presented in Chinese. Recruitment was carried out online, and all participants received money with a randomized value between 1-20 RMB as a reward. The description of the online listing is reprinted below.

Study Name: "Social Energy and Trust."

Description: Reflect on your personal thoughts and feelings towards an imagined situation and answer 34 questions. You will receive rewards after successfully submitting your answers.

\subsection{Experiment Design}

Each participant was asked to imagine themselves as the leader of an elephant protection organization who was extremely passionate about protection-related issues.

\section{Full description}

Please imagine that you are the president of an Elephant Protection Organization (EPO), aiming at stopping poaching, banning trades related to ivory carvings, and resolving human-elephant conflict to protect this magnificent endangered species. You are VERY PASSIONATE about your job: merely thinking about elephant protection stirs your motivation and concern.

After seeing an ivory carving in the black market, you feel enraged and indignant. You decided to purchase it even at a very high price to protect and prevent it from further harm and degradation. Then, you contacted an appropriate museum to arrange to send the statue to them for safe-keeping and, eventually, honored display. As it happens, they are short staffed and can only be available to receive it on a specific Sunday at 10:00 AM.

The person was then asked to imagine another organization member (Casper) who was either enthusiastic (HSE) or not (LSE) about elephant protection. The study was a one-way ANOVA (2X1) design, which manipulated two (high and low) levels of social energy. The only difference between HSE and LSE was the description of the attitude of the other person, Casper, towards animal protection.

\section{Full description}

When that Sunday arrives you discover unexpectedly that you must meet an important international supporter of the Elephant cause and cannot make the delivery yourself. It is Sunday morning, your staff say that the only person available seems to be a new member, Casper, with whom you have never talked before but-

/HIGH SE CONDITIONS: is very passionate about elephant protection, as you can see from his resume that he has organized several protection projects in Sub-Saharan Africa and achieved great success.

/LOW SE CONDITIONS: seems not so passionate about his job, as your co-workers have told you "Casper is not so enthusiastic about our mission, and he complains a lot about how much work there is."

As it happens, Casper is not in an optimistic financial situation - he and his family live on a pension and are relatively poor.

Casper's financial situation is addressed here in order to make it reasonable to not trust Casper and to further distinguish differences in trust between the two conditions, acting as a stimulus. In other words, there is a rational reason to label Casper with low trustworthiness because he has a strong incentive to sell the ivory statue.

Participants were randomly assigned to one of the two situations and filled out a questionnaire which assessed their levels of trust and other feelings, reactions, and explanations under three hypothetical situations of a) a successful 
delivery, b) failure due to a car accident, and c) failure due to Casper's selling the statue, varying in how warranted the trust was. Measures include: trust, warm feelings, expectation, delight, relief, gratitude, peace, sadness, guilt, regret, blame, betrayal, suspicion, ease of imagining the statue displayed in the museum, likelihood of visiting the museum, effort of reparing/finding the statue, effort of punishing Casper, blame of external factors (the untimely conference and bad luck), and whether Casper did what he should have done. Participants were instructed to rate the degree of these emotions from 1 (extremely uncharacteristic) to 5 (extremely characteristic).

To avoid differences caused by the order of the situations presented, I randomized the sequence of the three hypothetical scenarios in the questionnaire. (Please see Appendix for a complete list of the questionnaire.) All the distributions were normal, which is the reason for non-parametric test-analysis. Data were analyzed using SPSS 26.0.

\section{Results}

I calculated the score of each participant on the different scales by averaging their scores for the items. The means were compared for each question using ANOVA, with independent variables of Casper's attitude towards animal protection (high or low social energy), the participants' gender, and the participants' age. The participants' gender showed no significant differences, so I collapsed across age. The participants' age was only significant in some questions, so the exact presentation of the independent variable varies depending on the questions, leaving either $2 \mathrm{X} 2$ design or $2 \mathrm{X} 1$ with three specific situations. In each of the three situations below, I asked participants to forget about the previous situation and to imagine themselves in this new one. The measure used for all rating results span from 1 (extremely uncharacteristic) to 5 (extremely characteristic). Crosstabulations of social energy and different alternatives were also performed to verify the second hypothesis, which is the reason for granting trust, by applying three Pearson Chi-Square tests and calculating the asymptotic significance (2-sided).

\subsection{General Results}

\subsubsection{The Means of Trust and Positive Feelings}

Table 1. The Means of Trust and Positive Feelings

\begin{tabular}{|l|l|l|l|l|}
\hline & \multicolumn{2}{|l|}{ High/ Low Social Energy Groups } & & \\
\hline Dependent variables & High SE & Low SE & Significance & F \\
\hline Trust & 4.38 & 2.18 & $* * *$ & 153.62 \\
\hline Positive Feelings & 4.05 & 2.30 & $* * *$ & 61.25 \\
\hline
\end{tabular}

ns: Not statistically significant

*Effect is significant at the .05 level.

** Effect is significant at the .01 level.

*** Effect is significant at the .000 level.

Trust. This scale measured the participants' level of trust towards the other member. A higher score indicates people would trust Casper more to deliver the valuable statue, hold higher expectations regarding Casper's behavior, and would be more willing to expose other people's vulnerabilities to Casper. In the hypothesis, I predicted that participants with HSE would rate the other $(\mathrm{O})$ as more trustworthy compared to those with LSE. In the form above, the ANOVA test justified $\mathrm{F}=153.62$, $\mathrm{p}<.000$, on the relationship of trust as the dependent variable and social energy as the independent variable. Thus, the result strongly supports the first hypothesis that people in high social energy rate themselves as more trusting.

Positive Feelings. This scale measured the participants' general positive feelings towards Casper. A higher score indicated stronger agreement with statements such as "Generally he is a nice guy," and "I like Casper a lot." An ANOVA showed the main effect of social energy in terms of how participants feel about the other, $\mathrm{F}=61.25, \mathrm{p}<.000$. Interestingly, while HSE has a mean of 4.05 versus the 2.30 of LSE, this result strongly indicates that, despite the participants knowing almost nothing about Casper himself, they tend to have warmer feelings towards him based solely on the condition that he and "I" are mutually interested in animal protection. This result supports our third hypothesis of high social energy having more positive feelings towards the other member.

\subsubsection{The Reason of Trust}

Why do participants in HSE trust Casper more than those in LSE?

In order to answer this question, I provided a statement which asked the participants to rank four alternative explanations of why they trusted Casper. The four explanations were:

\section{A: Generally, people are cooperative.}

B: We have a strong bond in regard to elephant protection, so I know that he would do what I would do. In other 
words, in this shared interest, I know he values the situation as I do.

C: A successful delivery is intrinsically meaningful to him due to his passion towards elephant protection.

D: I am his superior, so he must follow my instructions.

The results of the Chi-Squared Test strongly supported the second hypothesis (that we are thinking the same thing) in that 28 participants in HSE selected alternative $\mathrm{B}$ as their first choice, while only 2 LSE participants selected it $\left(\mathrm{CHI}^{2}=\right.$ 130.56, $\mathrm{p}<.000)$. 17 LSE participants selected alternative D (I am the boss), while only 1 in HSE $\operatorname{did}\left(\mathrm{CHI}^{2}=110.65, \mathrm{p}\right.$ $<.000$ ), showing the predictions from a different perspective. Clearly, these results support the second hypothesis to an astonishing degree.

3.1.3 The Influence of Age and Social Energy on Trust

Table 2. AgeXSocial Energy and the Means of Trust

\begin{tabular}{|l|l|l|l|}
\hline & HSE & LSE & Significance \\
\hline $11-29$ & 3.00 & 1.77 & $* * *$ \\
\hline $30-45$ & 4.39 & 2.40 & $* * *$ \\
\hline $46-60$ & 4.50 & 2.64 & $* * *$ \\
\hline Total & 4.38 & 2.18 & $* * *$ \\
\hline
\end{tabular}

ns: Not statistically significant

*Effect is significant at the .05 level.

** Effect is significant at the .01 level.

*** Effect is significant at the .000 level.

Age. By collapsing the participants' age across social energy, the data reveals that those in the age group 46-60 are the most trusting compared to other ages in the same social energy group. Participants aged 11-29 were the least trusting towards Casper given the same conditions $(\mathrm{p}<.000)$. Thus, to some extent, the results support the conclusion that middle-aged participants are more trusting than teenagers, giving trust ratings that were 1.5 times larter in numerical values. This stark juxtaposition is interesting and requires further investigation.

Social Energy. In each of the age groups, participants in HSE rated Casper as significantly more trustworthy compared to those in LSE, $\mathrm{F}=24.54, \mathrm{p}<.000$. This again supports the first hypothesis from a multi-dimentional perspective. In each condition, the means of HSE are approximately 2 times of that of LSE.

\subsection{Situational Results}

Participants were then asked to answer questions and provide ratings regarding three specific situations: Casper successfully delivered the statue, Casper failed to deliver due to a "car accident," and Casper sold the statue due to his subjective willingness.

\subsubsection{Situation 1: Successful Delivery}

In this situation, I gave the description that Casper did in fact deliver the statue and that the handover was a huge success. Then, participants were asked to rate their feelings in each of the questions below, where 1 indicates extremely uncharacteristic and 5 means highly characteristic. The results are shown below.

Table 3. Means of Dependent Variables in Situation 1

\begin{tabular}{|l|l|l|l|l|}
\hline Situation 1 & \multicolumn{2}{l|}{$\begin{array}{l}\text { High/ Low Social Energy } \\
\text { Groups }\end{array}$} & & \\
\hline Dependent variables & High & Low SE & Significance & \multirow{2}{*}{ F } \\
\hline SEpectation of Success & 3.75 & 2.73 & $* * *$ & 15.84 \\
\hline Delight & 3.90 & 4.00 & $\mathrm{~ns}$ & .16 \\
\hline Relief & 3.68 & 4.23 & $*$ & 4.46 \\
\hline Gratitude & 4.18 & 2.93 & ns & 32.70 \\
\hline Peace & 3.73 & 3.53 & $\mathrm{~ns}$ & .52 \\
\hline Ease of Imagining Display & 4.05 & 4.10 & $\mathrm{~ns}$ & .50 \\
\hline Likelihood to See it in the Museum & 4.52 & 4.18 & $* * *$ & 3.20 \\
\hline Positive Feelings towards Casper & 4.20 & 3.48 & $* * *$ & 13.58 \\
\hline Casper did what he should have done & 4.27 & 3.08 & 22.30 \\
\hline
\end{tabular}

ns: Not statistically significant

* Effect is significant at the .05 level.

** Effect is significant at the .01 level. 
*** Effect is significant at the .000 level.

Expectation of Success. This scale assessed how the participants felt about the successful delivery. Higher scores indicate stronger agreements with statements such as, "I knew Casper would deliver the statue to the museum!" An ANOVA revealed that participants in high social energy rate the successful delivery as more "expected", with $\mathrm{F}=15.84, \mathrm{p}<.000$. This result is in concordance with the assessment of trust in the first section by supporting the crucial expectation component in a trusting relationship, as mentioned in the introduction. In other words, the results show that HSE participants rate the success as more expected, meaning that HSE scored better on one (expectation) of the two components (expectation and vulnerability) of trust. Participants who gave high ratings on this question indicated they had high expectations for Casper, indicating more trust in the first place, and that these expectations were fulfilled. The result supports the first hypothesis.

Delight. This item assessed whether the participants who were high vs. low in social energy experienced different levels of happiness and delight. In fact, there was no difference; however, they were all delighted.

Relief. This scale assessed whether the participants felt relaxed and less anxious after the delivery. High scores indicate agreement that participants felt less pressure after this success. An ANOVA revealed the relationship of low social energy, $\mathrm{F}=4.46, \mathrm{p}<.04$, on subjects' lower level of relief. This might be attributed to a low level of trust towards Casper in LSE, which led to higher psychological tension and stress that he might not deliver the statue. Since he did, they were more relieved.

Gratitude. This scale measured how thankful participants would feel. A high score indicates stronger agreement with statements such as "I feel deeply touched by the sacrifice he made," and "I really appreciate what Casper did." The ANOVA revealed a significant effect, $\mathrm{F}=32.70, \mathrm{p}<.000$, which indicated that participants in HSE are significantly more grateful, compared to those in LSE. This result is inconsistent with our previous prediction and supports our second hypothesis (HSE generates more positive feelings). This could possibly be attributed to a) more positive feelings in general generated under HSE conditions, b) HSE participants' higher levels of investment in emotions towards the statue, thus making the successful delivery more important psychologically thus being more grateful.

Peace. This scale assessed how peaceful and calm participants feel in each situations. The data yielded no significant results.

Ease of Imagining Display. This scale measured how easy it was for participants to imagine the statue displayed in the museum. Regardless of levels of social energy, participants seemed to easily imagine the ivory statue displayed, though there were no reliable differences. With means both higher than 4.15 out of 5 , I can conclude that, even without the engagement of another member, people are satisfied due to their own passion for the elephants. This result is consistent with past studies (Canavan \& Riggin, 2008) on social energy, which show that intrinsic motivation of $\mathrm{P}$ leads to more positive reports.

Likelihood to See it in the Museum. This item assessed whether participants would visit the statue in the museum. The ANOVA showed results of $\mathrm{F}=3.20, \mathrm{p}<.08$, a marginal effect on the dependent variable. The results support the conclusion that people experiencing HSE tend to care more about seeing the statue in the museum, although the difference is slight.

Positive Feelings towards Casper. This scale measured the quantity of positive feelings towards the other after the successful delivery. A high score shows participants had more warm feelings and positive emotions towards Casper in general. The ANOVA revealed a reliable result of $\mathrm{F}=13.58$ and $\mathrm{p}<.000$, where HSE had a mean of 4.20, and LSE 3.48. Therefore, the scores greatly improved in comparison to the general rating of the same question in the previous section, where LSE experienced an increase of 1.18 on a 5-point-scale. The result is consistent with our predictions and supports the third hypothesis.

Casper did what he should have done. This item assessed whether participants agreed that "Casper did what he should have done" in this successful delivery. A high score would indicate statements such as "He has strong/little interest in elephant protection, thus it is reasonable that he sacrificed the monetary value which could be meaningful to his family and prioritized the statue." The means provided a difference of 1.19 between HSE and LSE, and an ANOVA for this item is $\mathrm{F}=22.30, \mathrm{p}<.000$, indicating that the HSE's rates were significantly higher than the LSE's rates. This again indicates that HSE might occur with higher expectations, resulting in a better sense of responsibility and accordance with participants' previous predictions due to the established trust, warranting the first hypothesis.

\section{Reasons for the expectation.}

Why do participants in HSE rate the success as more expected compared to those in LSE? 
In order to provide solid evidence, investigations took place to collect the participants' reasons regarding why they did or did not expect the result. Participants were asked to rank the four following alternatives:

A: I know Casper CARES about the elephants as I do and will deliver the statue.

B: I can dismiss him at any time, and it is this THREAT that makes this safe delivery highly likely.

C: I know Casper cares but thought he would be more concerned to get the MONEY for his family.

D: Casper DOES NOT care much about the elephants or hard work, hence there's no reason to think he would deliver it instead of selling it, considering his family financial difficulties.

Alternative A is consistent with the descriptions of social energy, while alternative B describes aversive trust, which is the most common form of trust in superior-inferior working relationships. It is predicted that people in HSE would select A (that he would do what I would do) as the optimal option, and those in LSE would choose B (I am his boss). The results of Chi-Squared Test strongly supported the second hypothesis (that we are thinking the same thing) in that 36 out of 40 participants in HSE selected alternative A as their first choice, while zero LSE participants selected it $\left(\mathrm{CHI}^{2}=163.64, \mathrm{p}<.000\right) .26$ LSE participants selected alternative $\mathrm{B}$, while only $1 \mathrm{HSE}$ participant did $\left(\mathrm{CHI}^{2}=164.55\right.$, $\mathrm{p}<.000)$. These results strongly support the second hypothesis from another perspective by putting participants into the actual situation of successful delivery, instead of performing testing in imaginary situations of people's reasons for granting trust in the section of general results.

\subsubsection{Situation 2: Failed to Deliver due to Car Accident}

In this situation, participants were told that Casper sent "me" a text message that he had a car accident midway and failed to deliver the statue. He also told "me" the ivory statue was broken but conceivably REPAIRABLE. No other third-party evidence was to support Casper's arguments. I then asked participants to rate their feelings in the following measures.

Table 4. Means of Dependent Variables in Situation 2

\begin{tabular}{|l|l|l|l|l|}
\hline Situation 2 & High/ Low Social Energy Groups & & \\
\hline Dependent variables & High SE & Low SE & Significance & F \\
\hline Believe that it is the truth & 3.68 & 2.95 & $* *$ & 7.99 \\
\hline Sadness & 3.85 & 3.93 & ns & .13 \\
\hline Guilt & 3.35 & 3.45 & ns & .12 \\
\hline Relief & 2.73 & 2.53 & ns & .54 \\
\hline Gratitude & 2.78 & 3.40 & $*$ & 5.41 \\
\hline $\begin{array}{l}\text { Regret at paying high price at the } \\
\text { black market }\end{array}$ & 2.28 & 4.05 & & 45.56 \\
\hline Effort willing to repair & 4.13 & ns & ns & .50 \\
\hline $\begin{array}{l}\text { Willingness to reach out to help } \\
\text { Casper feel better }\end{array}$ & 4.18 & 3.95 & $*$ & .02 \\
\hline Blame own self & 3.35 & 4.15 & $*$ & 6.02 \\
\hline Blame Casper & 2.03 & 2.70 & $* * *$ & 4.63 \\
\hline Blame untimely conference & 3.05 & 2.55 & $* *$ & 17.57 \\
\hline $\begin{array}{l}\text { Suspect that Casper sold the statue } \\
\text { and told a lie }\end{array}$ & 2.22 & 2.00 & & 8.61 \\
\hline
\end{tabular}

ns: Not statistically significant

* Effect is significant at the .05 level.

** Effect is significant at the .01 level.

*** Effect is significant at the .000 level.

Believe that it is the truth. This scale measured whether participants believe Casper about the damaged statue and the car accident. A high score indicates stronger agreement with items such as "I totally believe in what Casper said," and "I strongly agree that the statue was harmed in the car accident instead of being sold." An ANOVA for this individual item revealed that, as expected, participants in HSE placed more trust in Casper with respect to his statements, even though no external facts are reported to support his messages, with $\mathrm{F}=7.99, \mathrm{p}<.01$. In LSE, participants might suspect the statue was secretly sold and Casper told a lie in order to escape with the money, indicating less trust was established in the first place. This strongly supports the first hypothesis that people with high levels of social energy tend to be more trusting.

Sadness. This item measured how sorrowful and mournful participants felt about the current situation. The ANOVA test did not yield significant results, but the means reveal that both groups rated high levels of sadness. 
Guilt. This scale assessed the level of culpability participants attribute to themselves. An ANOVA revealed that the manipulation did not impact guilt.

Relief. This item measured how relieved and reassured participants felt. The manipulation had no effect on relief, and both groups reported relatively low ratings of relief.

Gratitude. This scale assessed how thankful participants were of Casper. A high score indicates stronger agreement with items such as "I sincerely appreciate the sacrifice and effort Casper made when delivering the statue." An ANOVA revealed that, unexpectedly, people in LSE were more grateful, with $F=5.41, p<.02$. This result was different from our initial predictions because it is hypothesized that high social energy would trigger an increased amount of positive feelings, including gratitude. This was reversed in the actual data collected. There are two possible explanations. First, this could as well be due to the fact that people in LSE had lower levels of trust, and thus expectation, in the delivery. Witnessing the other becoming injured gave rise to more compassion and thankfulness. Second, from an HSE perspective, Casper did not deliver the statue so there is nothing to be thankful for.

Regret at paying high price at the black market. This scale measured whether participants were remorseful for their purchase. An ANOVA showed the main effects of low social energy in having more regrets, $F=45.56, p<.000$. This is in concordance with a common phenomenon. For example, a couple's pet dog was ill and they made every possible effort to treat the disease, but unfortunately it did not stop the dog from dying. In the hypothetical situation of the pet mentioned above, pet owners $(\mathrm{P} \& \mathrm{O})$ in high social energy of the pet $(\mathrm{X})$ would have fewer regrets, even though the result was not ideal. Given the chance to re-decide their behaviors, however, they would still be willing to pay a high price to try to treat the illness again, even though the actions might not change the outcome, due to the importance $\mathrm{X}$ has towards P. I believe similar reasons caused the differences in the dependent variable of regret paying high prices in the two social energy conditions.

Effort willing to repair and willingness to reach out to help Casper feel better. These scales measured the participants' willingness to remedy the current situation. However, the manipulation had no significant effects on these dependent variables, despite both HSE and LSE being surprisingly willing to make huge commitments to help Casper and repaire the statue, with average ratings above 4. I suspect that this is due to relationship between $\mathrm{P}$ and X; the power of $\mathrm{X}$ might contribute to the high ratings as well.

Blame own self. This scale assessed how participants felt about charcterizations of themselves in the event. A higher score indicates stronger agreement with statements such as "I think this car accident was my fault," and "If I hadn't ask Casper to deliver it, he wouldn't be injured and the statue would be fine." An ANOVA revealed the main effects social energy has on how much people attribute the responsibility to themselves, $\mathrm{F}=6.02, \mathrm{p}<.02$. When considering the means, people in HSE blame themselves nearly $30 \%$ more compared to those in LSE, leaving a huge gap between them. I believe this is possible due to 1) people in HSE knowing that Casper cares more and holding higher expectations for a positive result, so they blame themselves to resolve the cognitive dissonance, which is the mental discomfort of an individual that results from conflicting thoughts or facts; 2) as shown in past research conducted by Canavan \& Riggin (2008), high social energy is accompanied by more intense feelings of psychological separateness, hence HSE situations could assign more responsibility to the self. Psychological seperateness, in specific terms, means that "P" must first perceive another person, "O", as an object of physical and psychological particulars and separateness, and "O" perceives "P" in a similar manner (Heider, 1958). "P" and "O" recognize each other's independence and maintain their own individuality within contact, creating a seperated psychological condition in social energy.

Blame Casper. This measure assessed how participants felt about Casper's role in the delivery. A higher score indicates participants' stronger feelings of attributing the failure to the other. Interestingly, the ANOVA revealed the main effect of LSE blaming the other, $\mathrm{F}=4.63, \mathrm{p}<.04$. As predicted, LSE tends to blame Casper more, verifying the third hypothesis from the con's standpoint.

Blame untimely conference. This item measured how negatively participants rated the emergency conference which disrupted their schedule. A high score indicates stronger agreement with statements such as "If it weren't for the international meeting, this car accident wouldn't have happened." For blaming the conference, an ANOVA yielded a significant effect, $\mathrm{F}=17.57, \mathrm{p}<.000$, of HSE blaming the conference more that LSE. This result is interesting when compared to the previous item of blaming Casper. It seems that, when generalizing results from external factors (e.g. the other or the environment), different social energy groups react differently depending on the exact external factor which is influencing the outcome. I suspect that people in LSE blame O more when encountering failures, while those in HSE blame unchangeable external factors such as the conference, possibly due to the HSE participants' having more positive feelings toward $\mathrm{O}$ (as tested in the first hypothesis). However, further investigation is required.

Suspect that Casper sold the statue and told a lie. This item measured whether the participants distrusted 
Casper's statements, or suspicion, as opposed to trust. A high score indicates stronger agreement, such as "I don't believe in his message," and "He probably sold the statue secretely and escaped, the made-up message was only trying to reassure me." An ANOVA revealed that social energy had a strong effect on suspicion, $\mathrm{F}=8.61, \mathrm{p}<.01$. People in LSE are more sceptical of the other's subjective statements, as predicted. The data strongly backed up the hypothesis from the perspective of con, by supporting the idea that participants in LSE distrust and impose more suspicion on the other, compared to HSE.

\subsubsection{Situation 3: Failure due to Casper's Selling the Statue}

In this situation, I presented the scenario where solid evidence showed that Casper sold the precious ivory statue and escaped with the money. Then, I assessed the participants' feelings on the same scale as with previous situations.

Table 5. Means of Dependent Variables in Situation 3

\begin{tabular}{|l|l|l|l|l|}
\hline Situation 3 & High/ Low Social Energy Groups & & \\
\hline Dependent variables & High SE & Low SE & Significance & F \\
\hline Expected the Failure & 2.47 & 2.83 & $\mathrm{~ns}$ & 1.81 \\
\hline Guilt & 3.05 & 3.08 & $\mathrm{~ns}$ & .925 \\
\hline Blame own self & 3.38 & 2.65 & $* *$ & 7.16 \\
\hline Feel betrayed & 3.63 & 3.60 & $\mathrm{~ns}$ & .01 \\
\hline Blame untimely conference & 2.78 & 2.40 & $\mathrm{~ns}$ & 1.61 \\
\hline Effort willing to find it & 3.93 & 4.00 & $\mathrm{~ns}$ & .08 \\
\hline Effort to punish Casper & 3.05 & 4.35 & $* * *$ & 29.62 \\
\hline
\end{tabular}

ns: Not statistically significant

* Effect is significant at the .05 level.

** Effect is significant at the .01 level.

*** Effect is significant at the .000 level.

Expected the failure. This scale measured whether participants expected that Casper would sell the statue. A high score indicates stronger agreement with statements such as "I knew Casper would put his personal and family's financial condition before the common gains of the statue," and "I could foresee this terrible outcome through his previous attitude towards the protection job." There were marginal effects of social energy on the participants' attitudes, $\mathrm{F}=1.81, \mathrm{p}<.18$. Therefore, the scores of participants in low social energy conditions were higher than those of participants in other conditions.

Guilt. This item assessed how much participants ascribed the failure to their own misbehaviors. An ANOVA did not reveal significant differences between the conditions due to manipulation, but both groups had moderately high levels of guilt (means $>3$ ).

Blame own self. This scale measured how participants felt retrospectively about the role they played in the whole delivery. A higher score indicates stronger agreement with statements such as "I think this failed delivery was my fault because of wrong personal decision making." An ANOVA revealed the main effects of social energy on subjects, $\mathrm{F}=7.16, \mathrm{p}<.01$, in terms of blaming one's own self. People in HSE blame themselves $27.5 \%$ more on average. This, again, is consistent with our analysis of situation 2, where possibly increased levels of psychological separateness incurred more attribution of failure to the self.

Feel betrayed. This item measured whether the leader of the organization felt forsaken by Casper's selling of the statue. The ANOVA did not yield significant results, and participants in both conditions reported high levels of feeling betrayed.

Blame untimely conference. This scale assessed how negatively the participants rated the presence of the conference. A high score means that the participants thought "If it weren't for the emergency conference, there wouldn't have been such failure and we would have had other options." The ANOVA test showed that the manipulation did not impact the dependent variable, but the means revealed that HSE results in higher levels of blame, which is in concordance with the results of situation 2 .

Effort willing to find it. This item measured the participants' willingness to find the ivory statue and retrieve it from the black market. The data was not significant, but both groups in social energy were willing to put in a lot of effort, with means higher than 3.9. Based on the interpretations and findings from past research, I believe that the effort is due to the energy generated from the P-X circuitry, or the internal motivation of the self, regardless of the $\mathrm{O}$ component in the model.

Effort to punish Casper. This scale assessed how much effort participants would invest into punishing Casper, or pursuing legal action. A high score indicates stronger agreements with statements such as "I would do all that I could 
to find this person and give him what he deserves," or "I am planning to open a lawsuit." Participants with LSE would enforce punishment more with an additional 1.3 on the 5-point-scale, compared to HSE, F=29.62, $p<.000$. This is inconsistent with our predictions. Compared to previous thoughts that P in HSE might punish O more due to their caring more about the well-being of X, I suspect this inversed result is due to the participants' increased levels of tolerance in HSE.

\section{Reasons of the expectation.}

Although the means comparison did not yield significant results, why do participants in LSE rate the failure as more expected? I asked participants in both social energy conditions to rank the following alternatives of why they gave such a rating for the expected failure:

\section{A: I expected this result because Casper was not interested in this job in the first place, so there is no reason for him to deliver it instead of selling the valuable statue, considering his family's FINANCIAL difficulties.}

B: I expected this result because the statue is highly valuable; anyone would sell it for cash.

C: I didn't expect Casper to sell it because I thought that he would do what I would do (make the same choices and sacrifice) and deliver it.

D: I didn't expect this result because he was so interested in animal protection and I thought he valued the statue as much as I do, and that he would not even consider selling it for money.

Based on observations of the model, it is predicted that HSE participants would select C (I thought he would do what I would do) as the best alternative, while those in LSE would choose A (his low social energy and unfortunate financial conditions). The result of Chi-Squared Test and an ANOVA supported our predictions; 25 of 40 people in HSE selected $\mathrm{C}$, compared to zero in LSE $\left(\mathrm{CHI}^{2}=137.57, \mathrm{p}<.000\right) ; 33$ of all 40 participants in LSE selected A, while only 4 did in HSE $\left(\mathrm{CHI}^{2}=130.91, \mathrm{p}<.000\right)$. The results, from a third perspective, support the second hypothesis.

\subsection{Cultural Differences}

I are interested in reinforcing the universal validity of this work by experimenting with subjects from a wider range of cultural backgrounds. While I are confident in the construct validity of our design, it would be helpful to survey participants from different parts of the world with the same questionnaire. The different effects of this psychic energy could differentiate depending on different cultural backgrounds, varying from psychological separateness to social cohesion. For example, Eastern culture - particularly China, Japan, and India - stresses a sense of conformity in the population. From Confucius to Sakyamuni, it is derived from ancient culture and religion that gratitude and the attribution of errors to the self are moral actions. Thus, the influence of social energy on specific emotions is likely to vary.

\section{Discussion}

Social Energy is a new theory and the two hypotheses are also tested for the first time. I hypothesized that, first, people in High Social Energy (HSE) would be more trusting of another individual than would someone in Low Social Energy (LSE). Second, I predicted that HSE participants would explain the greater trust in an unusual way: 'I know O is thinking the same thing that I am thinking, so I trust him/her,' instead of attributing it to the fear of authorities, punishments, and violations.

The data provided remarkably strong support for both of these hypotheses, and they are accepted. In the case of the first hypothesis, HSE indicated that they were more trusting of Casper $(\mathrm{F}=153.62, \mathrm{p}<.000)$. Perhaps more illustrative, the data were even stronger in the support of the unusual explanation that "I trusted him because I know that he is thinking what I am thinking", instead of "I am his superior so he has to deliver." Here, not only did the HSE select that alternative from among four alternatives, but the LSE barely selected it (only 2 out of 40) and instead selected a sterner explanation ("Casper would deliver it because he was afraid of his boss"). In comparison, only one of the HSE selected this alternative. These results were way beyond chance ( $p<.000)$. For the most part in the rest of the study, HSE participants indicated that they liked Casper better, were more likely to believe him, were less likely to blame or punish him for a failure, and, even in face of failure, did not regret the great expense that their efffort to save the statue had cost them.

These results are interesting and important, partly because they introduce social energy as a newly established and powerful variable in understanding trust. Such method of building trust does not rely on reputation, apparent character, empathy, projection, or any usual predictors of trust. It is not even necessary that the truster has much personal contact with the trustee, beyond the knowledge that both are independently and intrinsically interested in the common goal X. The second hypothesis, which supports the unusual and thus far unnamed process through which the participant know 
what is in another person's mind (beliefs, motives, perspectives, and likely actions ONLY RELATED TO X), sounds a bit like mind-reading, or strange vibrations. However, as the first hypothesis suggests, it is yet the basis for potentially serious loss, if the trust is not delivered. In other words, people in everyday events do make trusting decisions for this reason. I recognize that this first study provides only a preliminary reason to indicate the reasons for trusting, and more content related to predicting or "knowing" another's behavior is worth exploring and investigating.

It is beyond common sense that this connection in social energy allows $\mathrm{P}$ and $\mathrm{O}$ to posess trust and understanding to such an extent. As depicted in the Lewis example, the two parties agreed on multiple points in the same ways. There is a new kind of data in neuropsychology, however, that may lend some credence to the validity and power of this way of 'knowing'. Fredrickson (2014) and others have recently shown that people who concentrate intensely on the same event (X) show similar brain patterns, occuring in the same time intervals. In her publication Love 2.0, Fredrickson elaborated on the resonance that occurs between individuals under certain conditions of connection, which shares the core with social energy.

Exploring the role of $\mathrm{X}$ in social energy with regard to trust and agreements on multi-characteristics might also be favorable. Based on past research and our results, it is almost as if $\mathrm{X}$ is active in contributing or offering itself to the trust, resonance or agreement. If we take artists as an example, then we recognize that an artist has a unique manner of making art, and that this way or style may, especially upon close (loving) attention, reveal itself to have many distinctive characteristics; Beethoven vs Mozart, Rodin vs Giacometti, Picasso vs Rembrandt, and Golden Retrievers vs Bichon-Frise - all offer us a unique set of dimensions that a lover or connoisseur knows, notices, and appreciates. It is in that sense that the $\mathrm{X}$ is more active than passive in the $\mathrm{P}-\mathrm{O}-\mathrm{X}$ configuration.

Future research should ascertain the essense of why "I know the other person is thinking the same way as I'm thinking." I propose that the next critical study surrounding this topic could both recruit participants who have multiple social energy topics in real life, as well as creating a hypothetical situation, and ask $\mathrm{P}$ to describe or predict what is in each other's mind, followed by surveying $\mathrm{O}$ to check the accuracy of such reports. I do not expect $\mathrm{P}$ and $\mathrm{O}$ to grasp exactly the same content in each other's minds, but I am eager to see whether the two components have the 'gist' of shared understanding. In other words, does social energy provide the lens through which to understand and connect two or more brains centering upon the activity of one common object or event. 80 participants is a limited number to for a quantitative survey, and I suggest future researchers expand the sample and repeat this experiment within multiple cultural settings. With further investigations, I believe the effects of such power could be far beyond establishing mutual trust.

\section{References}

Brewer, P. (2004). Public trust in (or cynicism about) other nations across time. Political Behavior, 26(4), 317-341. https://doi.org/10.1007/s11109-004-0899-6

Canavan, D. (2001). Social energy: The consequences of shared affect. Symposium given at the New England Psychological Association Conference in Danbury, Connecticut. Other presenters were Ed Diener, Christopher Peterson, and Joseph Mahoney.

Canavan, D. (2002). Social Energy: The Remarkable Consequences of Shared Enthusiasm. Unpublished Manuscript.

Canavan, D., \& Garinther, A. (2013). On Generosity, Well-Being, and Shared Enthusiasm. Unpublished Manuscript.

Canavan, D., \& Riggin, J. (2008). Social Energy in Cooperation and Competition. Unpublished Manuscript.

Canavan, D., \& Robinson, S. (2005). Comparing Positive and Negative Shared Interest in Social Energy. Unpublished Manuscript.

Castelfranchi, C., \& Falcone, R. (2011). Socio-Cognitive Theory of Trust.

Csikszentmihalyi, M. Flow: The Psychology of Optimal Experience. New York: Harper \& Row.

Deutsch, M. (1949). A theory of cooperation and competition. Human Relations, 2, 129-152. https://doi.org/10.1177/001872674900200204

Evans, A., \& Krueger, J. (2009). The Psychology (and Economics) of Trust. Social and Personality Psychology Compass, 3(6), 1003-1017. https://doi.org/10.1111/j.1751-9004.2009.00232.x

Fredrickson, B. (2014). Love 2.0: Creating happiness and health in moments of connection. New York: Plume.

Heider, F. (1958). The psychology of interpersonal relations. John Wiley \& Sons Inc. https://doi.org/10.1037/10628-000

Hill, C., \& O'Hara, E. (2006). A Cognitive Theory of Trust. Washington Univ. Law Rev. Retrieved from https://scholarship.law.umn.edu/faculty_articles/180. 
Kramer, R. M. (Ed.). (2006). Organizational trust: A reader. Oxford University Press on Demand.

Lewis, C. S., \& Barfield, O. (1955). Surprised by joy: The shape of my early life.

Rahn, W. M., \& Transue, J. E. (1998). Social trust and value change: The decline of social capital in American youth, 1976-1995. Political Psychology, 19(3), 545-565. https://doi.org/10.1111/0162-895X.00117

Rotter, J. B. (1967). A new scale for the measurement of interpersonal trust. Journal of Personality, 35(4), 651-665. https://doi.org/10.1111/j.1467-6494.1967.tb01454.x

Rousseau, D. M., Sitkin, S. B., Burt, R. S., \& Camerer, C. (1998) Not So Different after All: A Cross-Discipline View of Trust. Academy of Management Review, 23, 393-404. http://dx.doi.org/10.5465/AMR.1998.926617

Ryan, R. M., Huta, V., \& Deci, E. L. (2008). Living well: A self-determination theory perspective on eudaimonia. Journal of Happiness Studies: An Interdisciplinary Forum on Subjective Well-Being, 9(1), 139-170. https://doi.org/10.1007/s10902-006-9023-4

Simpson, J. (2007). Psychological foundations of trust. Current Directions in Psychological Science, 16(5), 264-268. https://doi.org/10.1111/j.1467-8721.2007.00517.x

Thielmann, I., \& Hilbig, B. E. (2014). Trust in me, trust in you: A social projection account of the link between personality, cooperativeness, and trustworthiness expectations. Journal of Research in Personality, 50, 61-65. https://doi.org/10.1016/j.jrp.2014.03.006

Wondra, J. D., \& Ellsworth, P. C. (2015). An appraisal theory of empathy and other vicarious emotional experiences. Psychological review, 122(3), 411-428. https://doi.org/10.1037/a0039252

\section{Appendix: Questionnaire}

Your gender:_M_F

Your age:

Your nationality:

Please imagine that you are the president of an Elephant Protection Organization (EPO), aiming at stopping poaching, banning trades related to ivory carvings, and resolving human-elephant conflict to protect this magnificent, endangered species. You are VERY PASSIONATE about your job: just thinking about elephant protection stirs your motivation and concern.

After seeing an ivory carving in the black market, you feel enraged and indignant. You decided to purchase even at a very high price, to protect and prevent it from further harm and degradation. Then, you contacted an appropriate museum to arrange to send the statue to them for safe-keeping and, eventually, honored display. As it happens, they are short staffed and can only be available to receive it on a specific Sunday at 10:00 AM.

When that Sunday arrives, you discover unexpectedly that you must meet an important international supporter of the Elephant cause and cannot make the delivery yourself. It is Sunday morning, your staff say that the only person available seems to be a new member, Casper, with whom you have never talked before but-

/HSE: is very passionate about elephant protection, as you can see from his resume that he has organized several protection projects in Sub-Saharan Africa and achieved great success.

/LSE: seems not so passionate about his job, as your co-workers have told you "Casper is not so enthusiastic about our mission, and he complains a lot about how much work there is."

As it happens, Casper is not in an optimistic financial situation - he and his family live on a pension and are relatively poor.

NOW, PLEASE PUT YOURSELF IN THIS SITUATION—REALLY IMAGINE IT!

Please use the following rating scale to answer the questions:

$1=$ Not at all; $2=$ Somewhat; $3=$ Moderately; $4=$ A great deal; $5=$ Completely

Q1. How much do you have warm feelings towards Casper?

Q2. How much would you trust Casper to deliver the statue?

Q3. Why would you trust him? Please rank EACH of the following reasons (1 is the most agreeable, 4 is the most disagreeable). 
A. I am his superior, so he must follow my instructions.

B. We have a strong bond in regard to elephant protection, so I know that he would do what I would do. In other words, in this shared interest, I know he values the situation as I do.

C. A successful delivery is intrinsically meaningful to him due to his passion towards elephant protection.

D. Generally, people are cooperative.

Q4. Why would you NOT trust him? Please rank EACH of the following reasons:

A. He's in a poor financial situation and needs the money he could get by selling the statue.

B. He is not passionate about elephant protection which makes selling it attractive.

C. Generally, people are not trustworthy.

\section{SITUATION 1}

Now suppose in that bind you did give Casper the statue to deliver and that he DID in fact deliver it safely:

Please use the same scale to answer these questions:

$1=$ Not at all; $2=$ Somewhat; $3=$ Moderately; $4=$ A great deal; $5=$ Completely

Q5. Did you expect this successful delivery?

Q6. WHY do you feel that it is expected/ unexpected?

Please rank how much you agree with each of the following reasons:

A. I know Casper cares about the elephants as I do and will DELIVER THE STATUE

B. I can dismiss him at any time, and it is this threat that makes this safe delivery highly likely.

C. I know Casper CARES but thought he would be more concerned to get the money for his family.

D. Casper DOES NOT care much about the elephants or hard work, hence there's no reason to think he would deliver it instead of selling it, considering his family financial difficulties.

(Remembering that Casper DID deliver it) Please rate the following:

Q 7. How delighted do you feel?

Q 8. How relieved do you feel?

Q 9. How grateful do you feel?

Q 9. How peaceful do you feel?

Q 10. How likely are you to imagine it displayed in the museum?

Q 11. How likely is it that you will go to see it in the museum?

Q 12. How much do you have warm feelings toward Casper?

Q 13. How much do you feel that he just did what he should have done?

\section{SITUATION 2}

Note: Please forget about the previous situation and put yourself into this new scenario.

Now suppose that in that bind you did give Casper the statue to deliver. Unfortunately, you received Casper's text message that crossing a busy street, he was hit by a car. Though he was not seriously hurt, the statue was broken but conceivably REPAIRABLE.

Please use the same scale to answer:

$1=$ Not at all; $2=$ Somewhat ; 3=Moderately ; $4=$ A great deal; $5=$ Completely

Q 14. To what extent do you believe it? 
Q 15. How sad do you feel?

Q 16. How guilty do you feel?

Q 17. Do you regret that you paid a lot for the statue at the black market?

Q 18. How relieved do you feel?

Q 19. How grateful do you feel?

Q 20. How much effort will you make to get the statue repaired?

Q 21. How much would you reach out to help Casper feel ok?

Q 22 How much do you blame yourself?

Q 23. How much do you blame Casper?

Q 24. How much do you blame bad luck that the international representative arrived unexpectedly?

Q 25. How much do you suspect that Casper sold the statue and told a lie?

\section{SITUATION 3}

Note: NOW, Please forget about the previous situation and put yourself into this new scenario.

Now suppose that in that bind you did give Casper this statue to deliver. Your staff reports that Casper sold the statue to a black market halfway and ran off with the money.

Please use the same scale to answer:

1=Not at all; 2=Somewhat; 3=Moderately; $4=$ A great deal; 5=Completely

Q26. Did you expect that Casper would sell this statue?

Q27. Why do you feel that it is expected/ unexpected? Please rank all answers below.

A. I expected this result because Casper was not interested in this job the first place, so there's no reason for him to deliver it instead of selling the valuable statue, considering his family's FINANCIAL difficulties.

B. I expected this result because the statue is highly valuable, anyone would sell it for cash.

C. I didn't expect Casper to sell it because I thought that he would do what I would do and deliver it.

D. I didn't expect this result because he was so interested in animal protection and I thought he valued the statue as I do, and that he would not even consider selling it for money.

Q 28. How much do you feel betrayed?

Q 29. How much do you blame Casper?

Q 30. How much do you feel guilty?

Q 31. How much do you blame yourself?

Q 32. How much do you blame bad luck that the international representative arrived unexpectedly?

Q 33. How much do you feel that you will try to get the statue back at the black market?

Q 34. How much effort would you invest to punish Casper or have the law punish him?

Thank you for completing this questionnaire! You would receive a red packet containing 1-20RMB as a reward.

\section{Copyrights}

Copyright for this article is retained by the author(s), with first publication rights granted to the journal.

This is an open-access article distributed under the terms and conditions of the Creative Commons Attribution license which permits unrestricted use, distribution, and reproduction in any medium, provided the original work is properly cited. 